\title{
Return to sports after COVID-19: a position paper from the Dutch Sports Cardiology Section of the Netherlands Society of Cardiology
}

\author{
G. C. Verwoert · S. T. de Vries · N. Bijsterveld · A. R. Willems · R. vd Borgh · J. K. Jongman · H. M. C. Kemps • \\ J. A. Snoek · R. Rienks · H. T. Jorstad
}

Published online: 13 July 2020

(c) The Author(s) 2020

\begin{abstract}
The coronavirus disease 2019 (COVID-19) pandemic has led to preventive measures worldwide. With the decline of infection rates, less stringent restrictions for sports and exercise are being implemented. COVID-19 is associated with significant cardiovascular complications; however there are limited data on cardiovascular complications and longterm outcomes in both competitive (elite) athletes and highly active individuals. Based on different categories of disease severity (asymptomatic, regional/ systemic symptoms, hospitalisation, myocardial damage, and/or myocarditis), in this point-of-view article we offer the (sports) cardiologist or sports physician in the Netherlands a practical guide to pre-participation screening, and diagnostic and management strategies in all athletes $>16$ years of age after COVID19 infection.
\end{abstract}

\section{G. C. Verwoert $(\bowtie) \cdot N$. Bijsterveld $\cdot H$. T. Jorstad Department of Cardiology, Amsterdam University Medical Centre, Amsterdam, The Netherlands \\ g.c.verwoert@amsterdamumc.nl \\ G. C. Verwoert \\ Department of Cardiology, Erasmus Medical Centre, Rotterdam, The Netherlands \\ S. T. de Vries \\ Department of Cardiology, Tjongerschans Hospital, Heerenveen, The Netherlands}

\section{N. Bijsterveld}

Department of Cardiology, Flevo Hospital, Almere, The Netherlands

\author{
A. R. Willems \\ Department of Cardiology, OLVG, Amsterdam, The \\ Netherlands \\ R. vd Borgh \\ Department of Cardiology, Laurentius Hospital, Roermond, \\ The Netherlands
}

Keywords COVID-19 - Sports · Exercise · Myocarditis $\cdot$ Recommendations

\section{Introduction}

With the implementation of less stringent coronavirus disease 2019 (COVID-19) restrictions for sports and exercise, healthcare professionals are faced with an increasing number of athletes-both competitive (elite) athletes and highly active individuals ( $>3 \mathrm{~h} /$ week of exercise)-seeking return-to-sports advice after recovery from COVID-19. This is challenging, as evidencebased recommendations for a return to sports after infectious episodes are limited and heterogeneous. Different proposals regarding the resumption of sports and exercise after COVID-19, e.g. from the Ameri-

\footnotetext{
J. K. Jongman

Department of Cardiology, Wilhelmina Hospital, Assen, The Netherlands

H. M. C. Kemps

Department of Cardiology, Maxima Medical Centre, Veldhoven, The Netherlands

Department of Industrial Design, Technical University, Eindhoven, The Netherlands

J. A. Snoek

Department of Sports medicine, Isala, Zwolle, The Netherlands

Isala Heart Centre, Zwolle, The Netherlands

R. Rienks

Central Military Hospital, Utrecht, The Netherlands
} 
can College of Cardiology's Sports and Exercise Cardiology Council, have recently been published [1, 2]. Based on different categories of disease severity, in this point-of-view article we offer the (sports) cardiologist or sports physician in the Netherlands a practical guide to pre-participation screening (PPS), and clinical management strategies in competitive (elite) athletes and highly active individuals $>16$ years of age after COVID-19.

\section{General recommendations}

Healthcare professionals should stay up-to-date and adhere to the most recent national recommendations from the National Institute for Public Health and Environment [3]. Healthcare professionals directly involved in athlete care should also stay up to date with recommendations from the NOC*NSF [4] and other relevant sports organisations. If national recommendations do not cover specific circumstances, public health considerations should always be taken into account and no unnecessary risks are acceptable that could lead to further spread of severe acute respiratory syndrome coronavirus 2 (SARS-CoV-2).

\section{Cardiac considerations for COVID-19}

Studies on critically ill, hospitalised patients have shown that infection with SARS-CoV-2 is associated with several cardiovascular complications [5-8]. The mechanism of cardiac injury from COVID-19 has not yet been fully elucidated, but is likely multifactorial [9, 10]. For an overview of all described complications, see Tab. 1. The background of the cardiovascular complications is extensively discussed elsewhere in this issue of the Netherlands Heart Journal.

As the precise mechanisms and long-term consequences of the interaction between SARS-CoV-2 and different (in particular cardiac) tissues are unknown, it is consequently unknown whether patients with (regional/systemic) symptoms are prone to cardiovascular sequelae after COVID-19 and what the influence of sports and exercise is on these potential sequelae.

\section{Specific considerations for athletes after COVID- 19}

Some considerations should be taken into account when assessing the scope of COVID-19 and potential cardiovascular complications in athletes. First, based on currently available reports, myocarditis leading to congestive heart failure and arrhythmias is diagnosed infrequently in patients with COVID-19, and no cases have been published describing elite athletes with SARS-CoV-2 myocarditis [10-14]. However, all-cause myocarditis is a significant cause of sudden cardiac death and sudden cardiac arrest (SCD/SCA) in young athletes [15], with case series reporting myocarditis as a potential cause of SCD/SCA in up to $8 \%$
Table 1 Cardiac considerations in COVID-19

Mechanism of cardiovascular injury
Hypoxaemia
Myocardial infarction
Systemic inflammatory response syndrome/cytokine storms
Microvascular ischaemia
Myocarditis
Hypercoagulability

[16]. Second, athletes are not a high-risk group for a severe course of COVID-19. Athletes in general and elite athletes in particular are younger, which is associated with a milder course of COVID-19 [17]. They also have fewer cardiac comorbidities, and a lower prevalence of obesity, diabetes mellitus and hypertension. Third, moderate exercise training reduces the risk, duration, and severity of viral infections in general, and regular exercise has positive effects on pulmonary function [18].

However, severe cases of COVID-19 requiring hospitalisation have been described in younger individuals without comorbidities [19]. Furthermore, older athletes or athletes with cardiovascular comorbidities who are at risk for a severe course of COVID-19 will wish to resume sports and exercise. The optimal approach to sports resumption in these individuals is unclear, as data are lacking on cardiovascular complications and cardiac injury in patients with mild or asymptomatic COVID-19. Considering the possible severe consequences of cardiac complications of COVID-19 in athletes, we recommend that an early diagnostic evaluation should take place in individuals aiming to return to sports after recovery from COVID19.

\section{Active COVID-19}

Athletes with active COVID-19 should cease all sports activities and undergo self-isolation at home for the entire symptomatic period [4]. While COVID-19-specific data are lacking, waiting 7-14 days after resolution of all symptoms, and a minimum of 10 days after onset of symptoms before resuming exercise seems reasonable. After that, gradual resumption of exercise and sports can be considered, based on the severity and duration of symptoms and after stratification if PPS is indicated.

\section{After recovery from COVID-19}

We stratify athletes that have recovered from the initial SARS-CoV-2 infection as:

- asymptomatic or local symptoms (non-hospitalised)

- regional or systemic symptoms (non-hospitalised)

- hospitalised and no myocardial injury

- hospitalised and myocardial injury

- myocarditis 


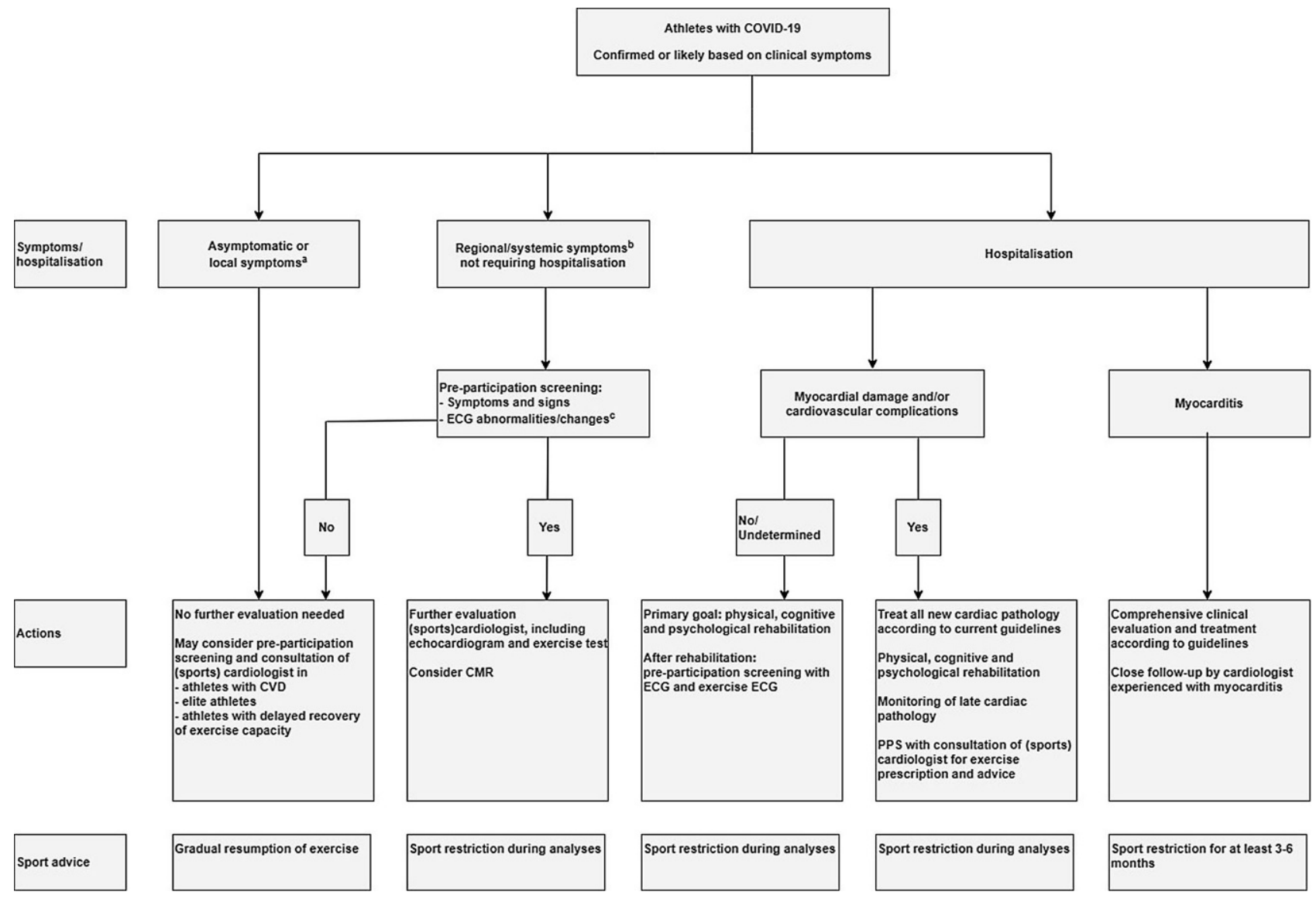

Fig. 1 Flowchart for stratification of athletes after COVID19 for pre-participation screening, diagnostic and therapeutic considerations. (ECG electrocardiogram, CMR cardiovascular magnetic resonance, CVD cardiovascular disease. ${ }^{a}$ Asymptomatic/non-systemic symptoms verified by critical

Table 2 Symptoms

\begin{tabular}{|c|c|c|}
\hline $\begin{array}{l}\text { Local (nose/ } \\
\text { throat) }\end{array}$ & $\begin{array}{l}\text { Regional (chest/head/ } \\
\text { neck) }\end{array}$ & Systemic \\
\hline Sore throat & Dry cough & Pyrexia \\
\hline Hoarseness & $\begin{array}{l}\text { Wet cough (sputum/ } \\
\text { mucus) }\end{array}$ & Chills \\
\hline $\begin{array}{l}\text { Blocked/ } \\
\text { plugged nose }\end{array}$ & Difficulty in breathing & Anosmia/ageusia \\
\hline Runny nose & $\begin{array}{l}\text { Rapid breathing/ } \\
\text { shortness of breath }\end{array}$ & Myalgia/arthralgia \\
\hline Sinus pressure & Chest pain & $\begin{array}{l}\text { Skin manifestations (ery- } \\
\text { thema, urticaria) }\end{array}$ \\
\hline Sneezing & Headache & $\begin{array}{l}\text { Gastrointestinal (nausea, } \\
\text { vomiting) }\end{array}$ \\
\hline $\begin{array}{l}\text { Altered/loss of } \\
\text { smell }\end{array}$ & Conjunctivitis & Encephalopathy \\
\hline $\begin{array}{l}\text { Altered/loss of } \\
\text { taste }\end{array}$ & & \\
\hline
\end{tabular}

Fig. 1 shows a flowchart to assist clinicians in stratification, and suggests PPS, diagnostic and therapeutic strategies, as well as giving general sports advice.

evaluation of signs and symptoms by general practitioner or other qualified healthcare professional. 'bee Tab. 2 for an outline of local, regional and systemic symptoms. 'Red flags suggestive of cardiac pathology in the 12-lead ECG are outlined in Tab. 3)

\section{Asymptomatic or local symptoms (non-hospitalised)}

PPS of athletes after asymptomatic infection or local symptoms (Tab. 2) of COVID-19 is not indicated if a critical evaluation of signs and symptoms (by general practitioners or other qualified healthcare professionals) is negative and shows a complete recovery. The chance of cardiac sequelae is probably negligible in such individuals. Feasibility, cost considerations and burdening of local health care systems should be considered if extending the indication for PPS to lowrisk individuals. However, a PPS and consultation by a (sports) cardiologist may be considered for specific groups. These groups include, but are not limited to, athletes with pre-existent cardiovascular pathology, elite athletes and athletes with impaired recovery of exercise capacity.

\section{Regional or systemic symptoms (non-hospitalised)}

PPS of patients after COVID-19 with regional or systemic symptoms (see Tab. 2 for an outline of regional and/or systemic symptoms) not requiring hospitalisation should be strongly considered. PPS includes criti- 
Table 3 Red flags in ECG suggestive of cardiovascular complications

Tachycardia at rest

Supraventricular or ventricular arrhythmias

Ventricular ectopy

High-grade atrioventricular blocks

Multiple-lead ST elevations

T-wave inversions

Pathological $Q$ waves

Left bundle branch blocks

Low QRS voltage (suggestive of pericardial effusion or myocardial oedema)

Signs of right ventricular pressure overload

cal evaluation of symptoms, physical examination and a 12-lead electrocardiogram (ECG). Red flags suggestive of cardiac pathology in the 12-lead ECG are outlined in Tab. 3. We emphasise that a 12-lead ECG is not the gold standard for the detection of myocarditis and other cardiovascular complication, and that a normal ECG does not rule out myocarditis in the presence of signs and symptoms suggestive of myocarditis [16, 20]. If needed, a (sport) cardiologist with experience in reading athletes' ECGs should be consulted when differentiating between ECG changes due to cardiac adaptation to sports and exercise and ECG abnormalities suggestive of cardiac pathology [21]. Using cardiac biomarkers to screen for myocarditis has been suggested [1]. However, we advise caution when using such a screening strategy. First, most athletes do not have previously documented baseline measurements and, second, elevated biomarker levels have been demonstrated after exercise in various athletes across different sports, without clear-cut clinical implications [22].

If the patient has completely recovered and is asymptomatic, and the 12-lead ECG is normal, gradual resumption of sports seems warranted. In the case of complaints or ECG abnormalities suggestive of cardiovascular complications, patients should be referred to a (sports) cardiologist for further evaluation. This evaluation should include at least an exercise test and an echocardiogram, but further diagnostic tests such as Holter monitoring or cardiac magnetic resonance imaging (CMR) can be considered. In the case of persistent cardiopulmonary complaints without a cardiac substrate, ruling out a pulmonary embolism should be considered.

\section{Hospitalised and no myocardial injury}

Patients with severe COVID-19 requiring hospital or intensive care admission, without signs of myocardial damage or cardiovascular complications, should be advised to first complete a comprehensive, multidisciplinary rehabilitation programme before resuming sports and exercise [23]. After completing rehabilita- tion, PPS and an exercise test should be performed before the patient resumes sporting activities.

\section{Hospitalised and myocardial injury}

In the case of myocardial damage and/or newly diagnosed cardiovascular complications during hospital admission, the primary focus should be to treat the relevant pathology according to current cardiovascular guidelines [20, 24-26]. After discharge, comprehensive rehabilitation should be prioritised with monitoring for late cardiac complications. A return to sports should take place only after a complete cardiovascular evaluation.

\section{Myocarditis}

If SARS-CoV-2 myocarditis is diagnosed, comprehensive clinical evaluation should take place, including CMR. In patients with myocarditis we advise intensive monitoring after discharge, and a sports restriction for at least 3-6 months, based on general myocarditis recommendations [20]. A return to sports should be evaluated by a multidisciplinary, expert team, and include input from sports cardiology and sports medicine.

\section{Limitations}

Due to the lack of data on athletes with COVID-19, all recommendations in this point-of-view article are based on expert opinion and expert consensus. With the explosive growth of publications on COVID-19, this statement should be interpreted only in the context of the most recent peer-reviewed publications and (inter)national society recommendations. A registry of COVID-19 cases among athletes and highly active individuals, including follow-up, is needed to provide an evidence-based approach for a return to sports after recovery from SARS-CoV-2 infection.

Acknowledgements We gratefully acknowledge the contribution of the following persons: E. Goedhart, P. Groenenboom, J. Hoogsteen, M. Moen, B. Pluim, J. Senden, G. Spaargaren, M. Thunissen, N. Wijne.

Conflict of interest G.C. Verwoert, S.T. de Vries, N. Bijsterveld, A.R. Willems, R. vd Borgh, J.K. Jongman, H.M.C. Kemps, J.A. Snoek, R. Rienks and H.T. Jorstad declare that they have no competing interests.

Open Access This article is licensed under a Creative Commons Attribution 4.0 International License, which permits use, sharing, adaptation, distribution and reproduction in any medium or format, as long as you give appropriate credit to the original author(s) and the source, provide a link to the Creative Commons licence, and indicate if changes were made. The images or other third party material in this article are included in the article's Creative Commons licence, unless indicated otherwise in a credit line to the material. If material is not included in the article's Creative Commons licence and your intended use is not permitted by statutory regulation or exceeds the permitted use, you will need to obtain permis- 
sion directly from the copyright holder. To view a copy of this licence, visit http://creativecommons.org/licenses/by/4.0/.

\section{References}

1. Phelan D, Kim JH, Chung EH. A Game plan for the resumption of sport and exercise after coronavirus disease 2019 (COVID-19) infection. JAMACardiol. 2020; https://doi.org/ 10.1001/jamacardio.2020.2136.

2. Baggish AD, JA; Kim, JH; Martinez, MW; Prutkin, JM. Blog British Journal of Sports Medicine [Internet]2020. Available from: https://blogs.bmj.com/bjsm/2020/04/24/theresurgence- of-sport-in-the-wake- of-covid-19-cardiacconsiderations-in-competitive-athletes/.

3. RIVM. https://www.rivm.nl/coronavirus-covid-19. Accessed 23 June 2020.

4. NOCNSF. https://nocnsf.nl/coronavirus-en-sport.Accessed 23 June 2020.

5. Clerkin KJ, Fried JA, Raikhelkar J, Sayer G, Griffin JM, Masoumi A, et al. COVID-19 and Cardiovascular Disease. Circulation. 2020;141(20):1648-55.

6. Kang Y, Chen T, Mui D, Ferrari V, Jagasia D, Scherrer-Crosbie M, et al. Cardiovascular manifestations and treatment considerations in covid-19. Heart. 2020; https://doi.org/ 10.1136/heartjnl-2020-317056.

7. Shi S, Qin M, Shen B, Cai Y, Liu T, Yang F, et al. Association of cardiac injury with mortality in hospitalized patients with COVID-19 in Wuhan, China. JAMA Cardiol. 2020; https:// doi.org/10.1001/jamacardio.2020.0950.

8. Zheng YY, Ma YT, Zhang JY, Xie X. COVID-19 and the cardiovascular system. Nat Rev Cardiol. 2020;17(5):259-60.

9. Duan J, Wu Y, Liu C, Yang C, Yang L. Deleterious effects of viral pneumonia on cardiovascular system. Eur Heart J. 2020;41(19):1833-8.

10. Gupta AK, Jneid H, Addison D, Ardehali H, Boehme AK, Borgaonkar S, et al. Current perspectives on coronavirus disease 2019 and cardiovascular disease: a white paper by the JAHA Editors. J Am Heart Assoc. 2020. https:// doi.org/ 10.1161/JAHA.120.017013

11. Hu H, Ma F, WeiX, Fang Y. Coronavirus fulminant myocarditis saved with glucocorticoid and human immunoglobulin. Eur Heart J. 2020; https://doi.org/10.1093/eurheartj/ ehaal90.

12. Inciardi RM, Lupi L, Zaccone G, Italia L, Raffo M, Tomasoni D, et al. Cardiac Involvement in a patient with coronavirus disease 2019 (COVID-19). JAMA Cardiol. 2020; https://doi.org/10.1001/jamacardio.2020.1096.

13. Kim IC, Kim JY, Kim HA, Han S. COVID-19-related myocarditis in a 21-year-old female patient. Eur Heart J. 2020;41(19):1859.

14. PaulJF, Charles P, RichaudC, Caussin C, DiakovC. Myocarditis revealing COVID-19 infection in a young patient. Eur Heart J Cardiovasc Imaging. 2020; https: / / doi.org/ 10.1093/ ehjci/jeaal07.
15. Harmon KG, Asif IM, Maleszewski JJ, Owens DS, Prutkin JM, Salerno JC, et al. Incidence and Etiology of Sudden Cardiac Arrest and Death in High School Athletes in the United States. Mayo Clin Proc. 2016;91(11):1493-502.

16. Halle M, Binzenhofer L, Mahrholdt H, Schindler JM, Esefeld K, Tschope C. Myocarditis in athletes: A clinical perspective. Eur J Prev Cardiol. 2020. https://doi.org/10. $1177 / 2047487320909670$

17. Ludvigsson JF. Systematic review of COVID-19 in children shows milder cases and a better prognosis than adults. Acta Paediatr. 2020;109(6):1088-95.

18. Zbinden-Foncea H, Francaux M, Deldicque L, Hawley JA. Does high cardiorespiratory fitness confer some protection against pro-inflammatory responses after infection by SARS-CoV-2? Obes (silver Spring). 2020; https://doi.org/ 10.1002/oby.22849.

19. CDC. Severe outcomes among patients with coronavirus disease 2019 (COVID-19) February 12-March 16, 2020. https://www.cdc.gov/mmwr/volumes/69/wr/ mm6912e2.htm. Accessed 23 June 2020.

20. Pelliccia A, Solberg EE, Papadakis M, Adami PE, Biffi A, Caselli S, et al. Recommendations for participation in competitive and leisure time sport in athletes with cardiomyopathies, myocarditis, and pericarditis: position statement of the Sport Cardiology Section of the European Association of Preventive Cardiology (EAPC). Eur Heart J. 2019;40(1):19-33.

21. Sharma S, Drezner JA, Baggish A, Papadakis M, Wilson MG, Prutkin JM, et al. International recommendations for electrocardiographic interpretation in athletes. J Am Coll Cardiol. 2017;69(8):1057-75.

22. Eijsvogels TM, Fernandez AB, Thompson PD. Are there deleterious cardiac effects of acute and chronic endurance exercise? Physiol Rev. 2016;96(1):99-125.

23. Thornton J. Covid-19: the challenge of patient rehabilitation after intensive care. BMJ.2020;369:m1787.

24. Ackerman MJ, Zipes DP, Kovacs RJ, Maron BJ. Eligibility and disqualification recommendations for competitive athletes with cardiovascular abnormalities: Task Force 10: The cardiac channelopathies: a scientific statement from the American Heart Association and American College of Cardiology. JAm Coll Cardiol. 2015;66(21):2424-8.

25. Bonow RO, Nishimura RA, Thompson PD, Udelson JE. Eligibility and disqualification recommendations for competitive athletes with cardiovascular abnormalities: Task Force 5: Valvular heart disease: a scientific statement from the American Heart Association and American College of Cardiology. J Am Coll Cardiol. 2015;66(21):2385-92.

26. Thompson PD, Myerburg RJ, Levine BD, Udelson JE, Kovacs RJ. Eligibility and disqualification recommendations for competitive athletes with cardiovascular abnormalities: TaskForce 8: Coronary artery disease: a scientific statement from the American Heart Association and American College of Cardiology. JAm Coll Cardiol. 2015;66(21):2406-11. 